\title{
Management in a Specific Environment in the Age of Globalization
}

\author{
Jozef Kubás ${ }^{1, *}$, Jana Štofková2 ${ }^{2}$, and Katarína Hollá ${ }^{1}$ \\ ${ }^{1}$ University of Zilina, Faculty of Security Engineering, Department of Crisis Management, Univerzitna \\ 1, 01026 Zilina, Slovakia \\ ${ }^{2}$ University of Zilina, Faculty of Operation and Economics of Transport and Communications, \\ Univerzitna 1, 01026 Zilina, Slovakia
}

\begin{abstract}
Research background: One of the important services in a specific mountain environment is the Mountain Rescue Service. The rescue services shall immediately provide the professional, medical, technical and other necessary assistance in an emergency on the instructions of the coordination centre or their emergency call operation centre. In the alpine environment, in addition to other rescue services, the Mountain Rescue Service implements organizational, technical and other measures to provide assistance in distress. This service is equipped for this purpose with technical and material resources.

Purpose of the article: The purpose of the article is to point out how globalization affects the visit of mountain regions in Slovakia. These visits are made up of people from different countries. In some cases, visitors get into trouble and demand the help they need to be provided at the appropriate level.

Methods: The article will use the analysis of the final reports of the Mountain Rescue Service for the past period. The method of comparison will also be used, where the individual years will be compared with each other with emphasis on certain criteria. Emphasis will also be placed on the circle of people who required help in distress when visiting mountain areas in Slovakia. Using deduction and induction, the obtained data will be correctly evaluated and logical conclusions drawn.

Findings \& Value added: Clearly processed and categorized statistics of interventions of the Mountain Rescue Service with an emphasis on the affiliation of affected people will help to identify target groups in the process of globalization, which are important to pay attention to. The article will make recommendations for improving the activities of the Mountain Rescue Service in the current era of globalization.
\end{abstract}

Keywords: Management; crisis management distress; Mountain Rescue Service; Integrated Rescue System.

\footnotetext{
* Corresponding author: jozef.kubas@uniza.sk
} 
JEL Classification: F59; $H 84 ; 118$

\section{Introduction}

Ensuring the safety of the population is becoming increasingly difficult due to the increasing negative effects on the environment in which they find themselves. The required level of safety achieved when it is not necessary to take specific measures for the normal course of the activity. Nevertheless, a number of negative phenomena arise that endanger lives, health, property or the environment. In order to be able to manage such events, it is necessary to have the strength and resources to manage them. To understand the issue, there is a need to clarify the basic concepts related to it. As important as clarifying the basic concepts is clarifying the environment to which the concepts relate.

The protection of life, health, property and the environment is a fundamental need of all countries in the age of globalization. This protection is provided by various components of the integrated rescue system. Getting to know the crisis management system of the basic components of this system brings further knowledge about the problem. We are currently seeing that some countries have difficulty dealing with serious crises. But in the age of globalization, many people travel for tourism, work, hobbies or other activities. Therefore, it is necessary that the state in which people are located be able to ensure security for all people. Crisis management needs to be constantly improved and adapted to the current time and its needs. This specific type of management can specified as a term referring to the profession of security managers with regard to crisis phenomena. It is also a specific management activity focused on managing the security of the organization. Crisis management is also a theory, a scientific discipline on security management with regard to crisis phenomena. Finally yet importantly, it expresses the art of managing security. In the event of an emergency or other crisis, a system need to help mitigate their negative impact on the environment. In order to be able properly design various measures, it is important to know the current state of affairs. This condition can identified, for example, from the number of negative phenomena in a territory over a period. Subsequently, it is necessary to focus on the forces and means that help them manage. This data will allow the crisis manager to propose appropriate measures to create a safe environment. Such an environment is important in the age of globalization, as the population, when visiting different states, also monitors whether they will be safe in a given area.

\section{Methods}

In the researched issues, it was necessary to perform an analysis of the current situation. The acquisition of a thought problem that required a solution was possible in the study of the issue in the era of globalization. Subsequently, it was necessary to search for available literature from other authors. Their information is intended to support the researched issues and point out possible solutions. The article focuses on Management in a Specific Environment. Specific services were the real components of an integrated rescue system. Due to the number of components, we narrowed the issue down to the Mountain Rescue Service. As part of its activities, a thorough analysis of the final accounts was performed. The analysis focused mainly on:

- Number of interventions,

- Number of mountain rescue members,

- Number of interventions of the Mountain Rescue Service according to the nationality of the victim.

Another important method used is comparison, which is based on searching for objects and phenomena in order to compare scientific knowledge. Emphasis was also being placed 
on number of interventions of the mountain rescue service and the circle of people who required help in distress when visiting mountain areas in Slovakia. This conversation was over a period of time, which allows a better understanding of the development of the problems.

\section{Results}

\subsection{Position and tasks of the Mountain Rescue Service in the integrated rescue system}

New global changes bring the need to adapt to current needs. These changes force the company to innovate its practices and improve its operations (Soltes et.al., 2019). Security is also an integral part. It is for it that the training of experts who are prepared for various unexpected situations is needed (Soltes et.al., 2016, Ristvej et.al., 2017). This preparation is supplemented by various modern technologies that can simulate various situations (Boros et.al, 2021). Hudakova et.al. (2017) state that it is necessary to achieve a certain education in order to be able to carry out their activities properly. Ristvej et.al. (2020) add that in order for work to be carried out effectively, it is also necessary to have the right technical equipment. This equipment should be directly adapted to the activities of the components that need it for specific tasks. Due to the scale of the issue, attention is paid to one specific component and that is the Mountain Rescue Service. In the environment of the Slovak Republic, they use various rescue components of the integrated rescue system. Figure 1. shows their composition

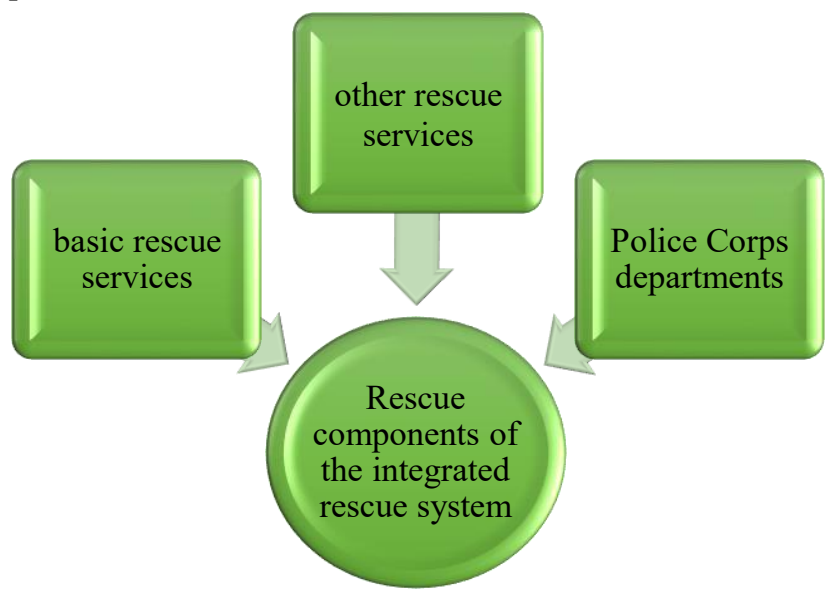

Figure 1. Composition of the integrated rescue system

Source: Act no. 129/2002

The mountain rescue service is included among the basic rescue services. It is the basic rescue services that require the following activities:

- assistance without delay in the professional, medical, technical and other necessary assistance within the framework of the commitment on the basis of an instruction from the coordination centre or its emergency call operation centre,

- to inform organizational, technical and other measures about the provision of assistance in distress and for this purpose they are equipped with technical and material means,

- $\quad$ participate in training - Training of rescue services of the integrated rescue system includes: 
on the principles of organization and ensuring the activities of the coordination centre,

- on the method of ensuring the reception, evaluation and implementation of the emergency call response by the coordination centres and emergency call operation centres,

- on the method of ensuring voice and data transmission of information between the rescue services of the integrated rescue system,

$\circ \quad$ on the method of management and principles of coordination of activities of rescue services of the integrated rescue system at the place of intervention,

○ on the provision and method of using the automated system of support for the management and processing of information of the coordination centres and operational centres of emergency calls and the keeping of documentation and records of the activities of the basic rescue services.

- process data on its activities, forces and resources and submit them to the district office in the seat of the region by the end of February for the previous calendar year; in the case of emergency medical service providers, also to the Ministry of Health (Act 129/2002).

Details of the organization of the mountain service are regulated by the statute, which is approved by the Ministry. The Mountain Service manages property owned by the Slovak Republic and is based in the High Tatras. Mountain service in mountain areas and caves in particular:

- $\quad$ organizes and performs rescue activities,

- provides information related to the safety of persons,

- takes preventive measures related to the safety of persons, especially in the event of an avalanche,

- $\quad$ participates in the search for a missing person,

- comments on the marking of routes and their marking,

- ensures the operation of rescue and reporting stations of the mountain service,

- provides health care according to a special regulation5a) in cooperation with the emergency medical service.

- performs tasks within the integrated rescue system,

- issues a methodology for the exercise of professional competence,

- exercises professional competence,

- issues a certificate of professional competence,

- provides material and technical equipment of persons who participate on the basis of a contract for the performance of mountain service tasks

- decides according to a special regulation on the recognition of professional competence to perform rescue activities acquired abroad,

- provides co-operation in documenting an event resulting in death or damage to health in a hard-to-reach place,

- is entitled to make a video record or other record of the cause and course of the rescue activity, including the receipt of an emergency call, which it keeps for three years from its occurrence, in order to document the rescue activity,

- performs training of dogs to perform rescue activities,

- $\quad$ supervises compliance with the obligations set out in this Act,

- cooperates with state bodies, local self-government bodies, civic associations, other legal entities and natural persons in the performance of tasks under this Act,

- cooperates with international organizations operating in the field of mountain rescue, in which it represents the Slovak Republic (Act No. 544/2002 Coll.)

The Mountain Service in mountain areas shall locate and maintain, in consultation with the owner, manager or user of the property, places warning, information and other devices 
related to the safety of persons and security devices on dangerous sections of routes that it designates. For a fee, the mountain service may contribute to the safety of sporting events and other public events and provide safety and rescue services to the operator of the ski run and the operator of the cableway installation if the ski run is in an area which may be endangered by avalanches. The Mountain Service publishes on its website data on persons with professional competence to perform rescue activities in the scope of name, surname and type of rescue activity.

The law also entitles the mountain service to permission. A member of the mountain service, in the exercise of his rights, shall prove himself by a service card of the mountain service. The mountain service processes personal data of persons in the range of name, surname, date of birth and address of residence. A member of the mountain service in the performance of tasks and another person who carries out an activity organized by the mountain service are entitled to:

- $\quad$ enter the mountain area and the cave by means of mountain service vehicles without restriction,

- $\quad$ use cars with special warning signs, signal pistols, explosives and explosive articles in accordance with a special regulation,

- $\quad$ use equipment intended for passenger cable transport free of charge and preferably during rescue activities, preventive activities in the event of an avalanche threat and supervision of compliance with the provisions of this Act,

- to cross the state border for the necessary time and to the necessary extent under the conditions stipulated by an international agreement by which the Slovak Republic is bound,

- issue guidelines on the safety of persons in mountain areas,

- look at the book of outings and exits and request information from it,

- when proving rescue activities or searching for a missing person, to prove the identity of the person to whom the rescue activity or search relates, or to prove the identity of the person in connection with the imposition of fines in block proceedings under the Act (Act No. 544/2002 Coll.).

\subsection{Activity of the Mountain Emergency Service in the Conditions of Globalization}

During their operation, the basic components of the integrated system receive the necessary training and coaching to deal with difficult situations (Polorecka, et. al., 2020). During its activities, the Mountain Rescue Service is ready to intervene in the area of its competence. When dying, the individual areas in which it intervenes can be affected differently on ski slopes or in mountain areas. Figure 2. shows the number of interventions in comparison with the number of members of the Mountain Rescue Service. 


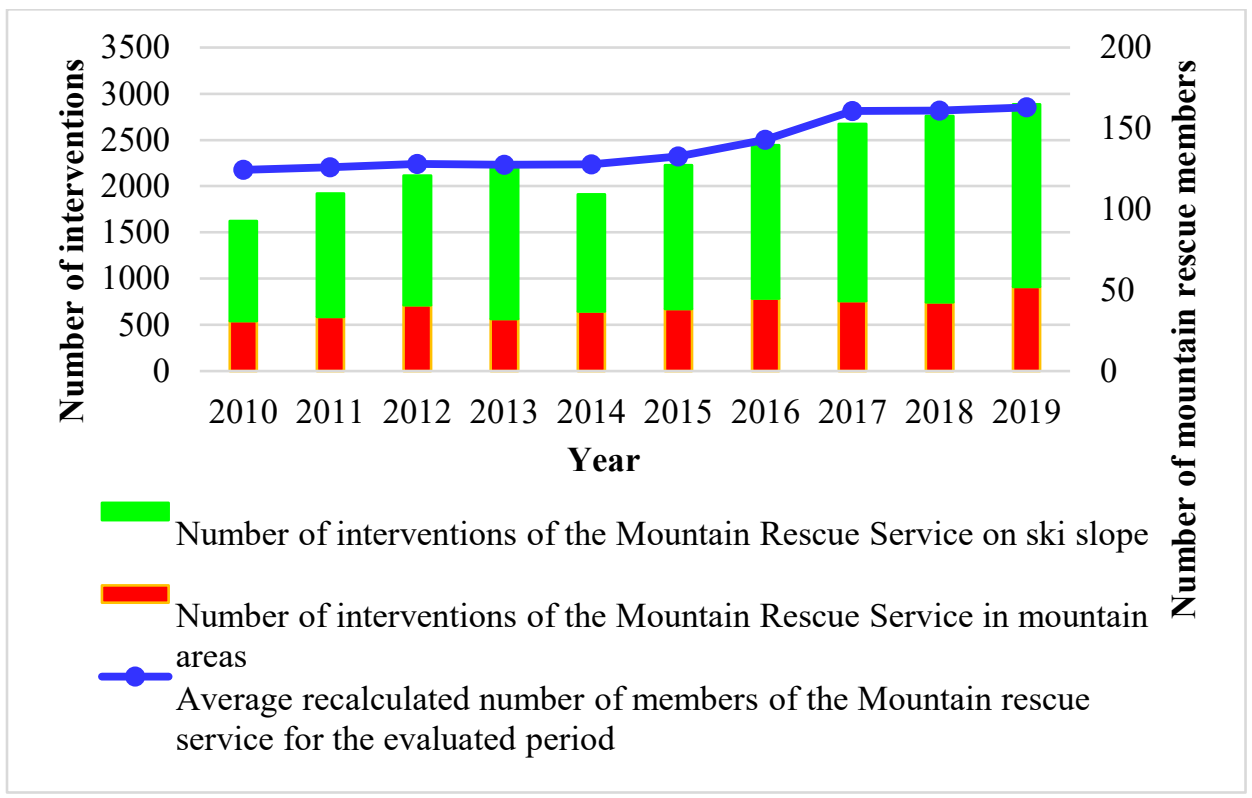

Figure 2. Numbers of interventions and members of the fire brigade for the period 2010-2019

Source: Annual reports of the Mountain rescue service (2010-2019)

The comparison shows that the number of interventions increased on average over the period under review. Adequate forces and resources need allocated to deal more interventions. Among these forces, we can include members of the Mountain Rescue Service. Their number increased on average in the monitored period, which enables more effective, involvement in the case of the number and complexity of interventions. However, in order to increase the number of employees, it is necessary to allocate a larger amount of funds. This can be a problem here, as the budgets of public administration and organizations connected to them are limited (Šoltes and Stofkova, 2019). According to Ahmad et al (2021). Ahmad, et al. (2021) point out that the solution could be in providing various development projects. These projects need to be tailored to specific needs, so it is important to pay due attention to the activities of hot rescue services. It is precisely such projects, but also the financing of various organizations that should be part of national economic growth (Ginevicius et. al, 2020). According to Klietik et al. (2020), it is important to anticipate possible changes in the economy and, given this, to adequately set a budget plan.

Another important aspect that needs attention is the nationality of the disabled person. The era of globalization creates opportunities to travel within countries (Stofkova et al., 2020). From the point of view of globalization, such identification will make it possible to approach the attendance of mountain areas in Slovakia by foreign tourists. Figure 3. shows that most of the people who needed help were from Slovakia. Subsequently, the inhabitants of Poland held the second largest representation. This is what shows the importance of crossborder cooperation between the various components of the integrated rescue system, as sometimes the intervention takes place in border areas. The third representation during all monitored years was the population of the Czech Republic and subsequently the 
representation of the population of Hungary. The others groups were from different countries or their nationality wasn't ascertained.

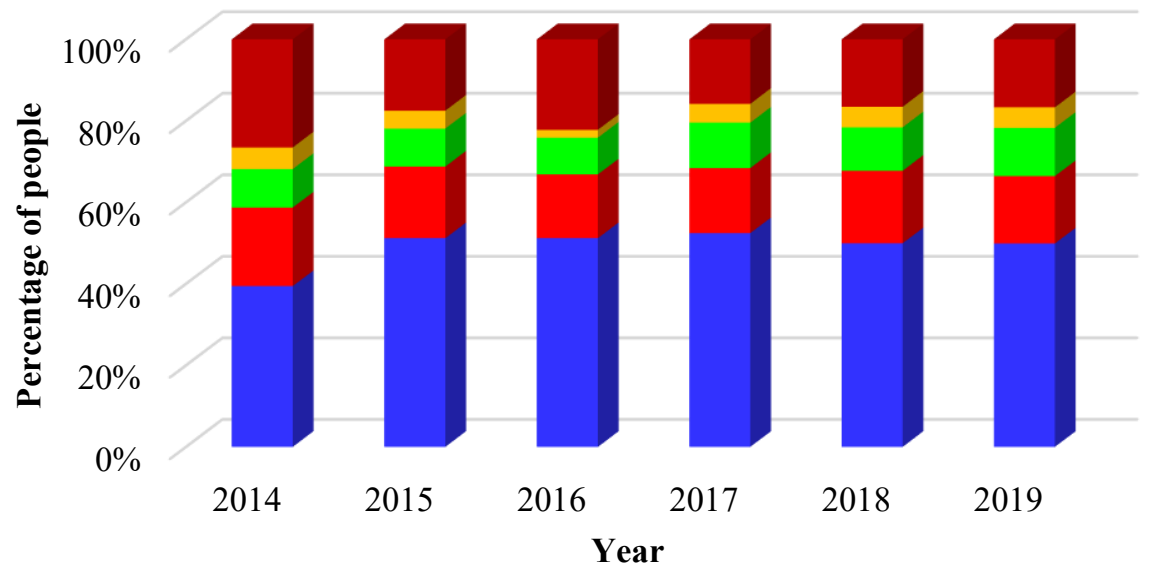

- Slovak $\square$ Polish $\square$ Czech $\square$ Hungarian $\square$ Other

Figure 3. Number of interventions of the Mountain Rescue Service according to the nationality of the victim

Source: Annual reports of the Mountain rescue service (2014-2019)

\section{Discussion and Conclusion}

According to Maslow's pyramid of human needs, safety, as the primary human need, is second only to human physiological needs. Security is essential for the functioning of life on earth. Security itself or the feeling of security has a great influence on the functioning of the state, all its institutions, organizations and also on man as an individual. At present, armed conflicts at regional level can be considered almost unlikely, in contrast to violence, which is relatively common and has a negative impact on security. To maintain a sense of security, it is necessary to protect human health and life, ensure the safety of property, protect the environment, maintain in the organization continuity in main and supporting activities, guarantee sufficient information for every decision and protect this information (Belan, 2015). This safety can be negatively affected by various emergency events or crisis events. The resolution of emergencies requires a rapid response to the occurrence of an emergency events in the affected area. A system that responds to emergencies, carries out rescue work and carries out emergency assistance activities is called an integrated rescue system. In the article, we focused on its one basic component, namely the Mountain Rescue Service. We analysed and compared its activities over a period of time. The results point to the need to spend funds on the activities of the Mountain Rescue Service. It is precisely its activity that is important in the age of globalization, as it helps all people, regardless of nationality, within its scope.

Moutanin Rescue Service works with the public and private sectors to create a safe environment. Such cooperation will improve their position and the ability to communicate better with the public (Kiryluk, et al., 2020). It is also important to expand the number of rescuers performing emergency interventions. When hiring new members, it is necessary to place them correctly in the team and create suitable conditions for cooperation (Ogunfowora 
et. Al., 2020.) It is important that the state also supports all components that create a security environment and motivates people to want to work in them. (Rebollo-Sanz and RodriguezPlanas, 2020).

\section{Acknowledgements}

This paper was supported by project VEGA 1/0518/19, VEGA 1/0768/19, VEGA 1/0581/19 and „MREdu: Pogotowie Górskie - edukacja transgraniczna ratowników górskich w Polsce i na Słowacji".

\section{References}

1. Act no. 129/2002 Coll. on an integrated rescue system.

2. Act no. 544/2002 Coll. Mountain Rescue Service Act.

3. Ahmad, M., et.al. (2021). Modelling the dynamic linkages between eco-innovation, urbanization, economic growth and ecological footprints for G7 countries: Does financial globalization matter? Sustainable Cities and Society, 70, Art. No. 102881.

4. Belan, L. (2015). Security and risk management. 1st edition. Žilina: EDIS.

5. Boros, M., Zvakova, Z., Soltes, V., \& Vel'as, S. (2021). What is the role of private intelligence in the Slovak Republic? Legal and practical aspects of private detective services. Security Journal.

6. Ginevicius, R., Kliestik, T., Stasiukynas, A., \& Suhajda, K. (2020). The Impact of National Economic Development on the Shadow Economy.Journal of Competitiveness, 12(4), 39-55.

7. Hudakova M., Buganova, K., \& Dvorsky, J. (2017). Increasing Integration of Practical Activities to the Higher Education in the Risk Management in Slovakia. 10th International Conference of Education, Research and Innovation (pp. 996-1003).

8. Kiryluk, H., Glinska, E., Barkun, Y. (2020). Benefits and barriers to cooperation in the process of building a place's brand: perspective of tourist region stakeholders in Poland. Oeconomia Copernicana, 11(2), 289-307.

9. Kliestik, T., Valaskova, K., Lazaroiu, G., Kovacova, M.,\& Vrbka, J. (2020). Remaining Financially Healthy and Competitive: The Role of Financial Predictors. Journal of Competitiveness, 12(1), 74-92.

10. Mounatin Rescue Services. Annual Report of the Mountain Rescue Service for the year. https://www.hzs.sk/riaditelstvo/vyrocne-spravy/.

11. Ogunfowora, B., Weinhardt, J. M., \& Hwang, C. C. (2020). Abusive Supervision Differentiation and Employee Outcomes: The Roles of Envy, Resentment, and Insecure Group Attachment. Journal of Management, 47(3), 623-653.

12. Polorecka, M., Svetlik, J., \& Mitrengova J. (2020). Professional Education and Preparation for the Performance of Professional Fire Services in the Field of Environmental Interventions. 14th International Technology, Education and Development Conference. Valencia, Spain (pp. 5048-5053).

13. Ristvej, J., Lacinak, M., \& Ondrejka, R. (2020). On Smart City and Safe City Concepts. Mobile Networks \& Applications, 25(3), 836-845.

14. Ristvej, J., Sokolova, L., Starackova, J., Ondrejka, R., \& Lacinak, M. (2017). Experiences with Implementation of Information Systems within Preparation to Deal 
with Crisis Situations in Terms of Crisis Management and Building Resilience in the Slovak Republic. International Carnahan Conference on Security Technology (Iccst).

15. Rebollo-Sanz, Y. F., \& Rodriguez-Planas, N. (2020). When the Going Gets Tough ... Financial Incentives, Duration of Unemployment, and Job-Match Quality. Journal of Human Resources, 55(1), 119-163.

16. Stofkov, Z., \& Sukalova, V. (2020). Sustainable Development of Human Resources in Globalization Period. Sustainability, 12(18), Art. No. 7681.

17. Soltes, V., Stofkova, K. R., \& Lenko, F. (2020). Socio-economic consequences of globalization on the economic development of regions in the context of security. 19th International Scientific Conference Globalization and Its Socio - Economic Consequences, Sustainability in the Global-Knowledge Economy.

18. Soltes, V., \& Stofkova, Z. (2016). Security as an Aspect of the Quality Management in Local Self-Government in Age of Globalization. 16th International Scientific Conference on Globalization and its Socio-Economic Consequences (pp. 2060-2067).

19. Soltes, V., \& Stofkova, Z. (2019). Financing of Cultural Management in Regional Selfgovernment. International Scientific Conference on Marketing Identity - Offline Is the New Online (pp. 1078-1088). 